\title{
Retrograde venous bullet embolism after thoracic gunshot
}

\section{Embolia balística venosa retrógrada após ferimento torácico por arma de fogo}

\author{
Leonardo Pessoa Cavalcante ${ }^{1}$, Marcos Velludo Bernardes', Ricardo Dias da Rocha', \\ Marcos Henrique Parisati', José Emerson dos Santos Souza', Antônio Oliveira de Araújo', \\ Patrícia de Souza Lacerda', Raquel Magalhães Pereira ${ }^{2}$
}

\begin{abstract}
Bullet embolism is a rare complication of penetrating gunshots. We present a case of a 24-year-old man with a gunshot wound in the left scapular area, with no exit wound. Abdominal X-rays and a computed tomography (CT) scan suggested that the bullet was located within the intra-abdominal topography (intrahepatic), but laparotomy revealed no intra-abdominal injuries. After surgery, a sequential CT scan showed that the bullet had migrated to the right internal iliac vein (IIV). Venography confirmed the diagnosis of right IIV embolism and the decision was taken to attempt snare retrieval of the bullet, which was unsuccessful. It was therefore decided to leave the missile impacted inside the right IIV and the patient was put on oral anticoagulation. The patient recovered and was event free at 6 months' follow up.
\end{abstract}

Keywords: wounds, gunshot; embolism; tomography; phlebography; iliac vein.

\begin{abstract}
Resumo
Embolia balística é uma complicação rara de ferimentos por arma de fogo. Apresentamos um caso de um homem de 24 anos, vítima de um ferimento por arma de fogo em hemitórax posterior esquerdo (região escapular), sem orifício de saída. Radiografias e tomografia computadorizada do abdome evidenciaram um projétil em topografia intraabdominal (intra-hepática); no entanto, a laparotomia exploradora demonstrou ausência de lesões intra-abdominais. Após a cirurgia, novo exame tomográfico revelou a migração da bala para a região da veia ilíaca interna (VII) direita. Realizada uma flebografia, esta confirmou a migração do projétil para a VII direita; tentou-se retirar o projétil durante o procedimento, sem sucesso. Optou-se, então, por deixá-la impactada na VII direita e manter o paciente em anticoagulação oral. O paciente evoluiu sem intercorrências até o sexto mês de seguimento.
\end{abstract}

Palavras-chave: ferimentos por arma de fogo; embolia; tomografia; flebografia; veia ilíaca.

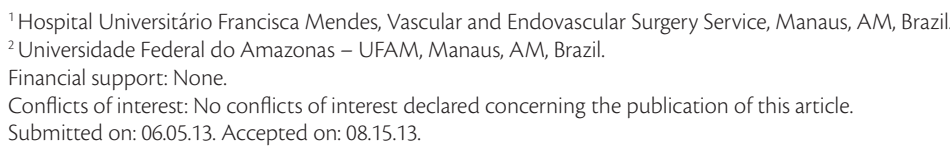




\section{INTRODUCTION}

Bullet embolization of the arterial or venous systems is a rare complication of penetrating gunshot injuries. Most shootings result in an entrance and exit wound or, in the absence of an exit wound, a projectile located in the injury area ${ }^{1,2}$.

Due to their rarity, bullet embolisms are responsible for considerable diagnostic confusion. Careful evaluation of projectile trajectory is essential to identify all related injuries ${ }^{3}$. Workup must investigate both clinical manifestations and projectile location using preoperative and intraoperative imaging ${ }^{2,4}$. Treatment of this condition is decided on a case-bycase basis, and may or may not involve removal of the projectile $e^{4,5}$.

We present a case of venous bullet embolism after a gunshot to the chest.

\section{CASE REPORT}

A 24-year-old man presented at the emergency department with a gunshot wound in the posterior left chest (scapular area - Figure 1) and no evidence of an exit wound.

The patient was hemodynamically stable, but exhibited dyspnea and decreased breath sounds from the left chest. The remainder of the physical examination was unremarkable. The left thorax was drained through a chest tube and, on the basis of X-ray and CT (non-contrast enhanced) evidence that the bullet was located in intra-abdominal (intrahepatic) topography (Figure 2A, 2B), the patient underwent exploratory laparotomy that did not show intra-abdominal/phrenic injuries and failed to locate the projectile. Embolism was therefore suspected, and the decision was taken to monitor the bullet's position with sequential CT scans.

The first postoperative contrast-enhanced thoracic and abdominal CT scan showed fractures of the third, fourth and fifth ribs, a fractured scapula, a pulmonary contusion restricted to a trail in the apex of left lung (Figure 3), minimal left pneumothorax, pneumoperitoneum, normal contrast filling of the aorta and inferior vena cava (IVC) and the projectile inside the right internal iliac vein (IIV) (Figure 4A, 4B), with no related symptoms.

One week after the shooting, the patient was referred to an endovascular laboratory and underwent iliocavography via left femoral vein puncture, which confirmed the bullet's position and the diagnosis of embolism of the right IIV (Figure 5).

During the same procedure, a planned attempt at snare retrieval of the bullet was conducted, but without success. Since the bullet was impacted inside the right IIV and there was no opacification of the right IIV distally to the bullet's location (thrombosis could not be ruled out), the decision was taken to leave it in place. This decision was based on the patient's absence of symptoms, the bullet's topography and the possibility of causing additional damage/thrombus embolization by forced removal.

The patient recovered uneventfully after the endovascular procedure, but was kept in hospital in view of the chest tube and to be given anticoagulants. He was discharged 5 days later to outpatients followup with control X-rays (one week and 30 days later), which demonstrated that the projectile remained in the same topography. He remained asymptomatic at 6 months follow-up when another control X-ray found no evidence of projectile dislodgement and it was decided to suspend oral anticoagulation at that point.

\section{DISCUSSION}

Bullet embolism is a rare and challenging complication of gunshot injuries ${ }^{1-9}$ with $0.3 \%$ incidence in 7,500 patients in a 10-year report ${ }^{2}$ and fewer than 200 cases reported in the literature since $1900^{1,2,9}$. For a projectile to enter systemic circulation, it must have just enough energy to penetrate a blood vessel or the heart, but not enough to transfix the structure. Since this is unlikely, in most cases gunshot injuries tends to destroy vessels, rather than merely penetrate them ${ }^{5}$.

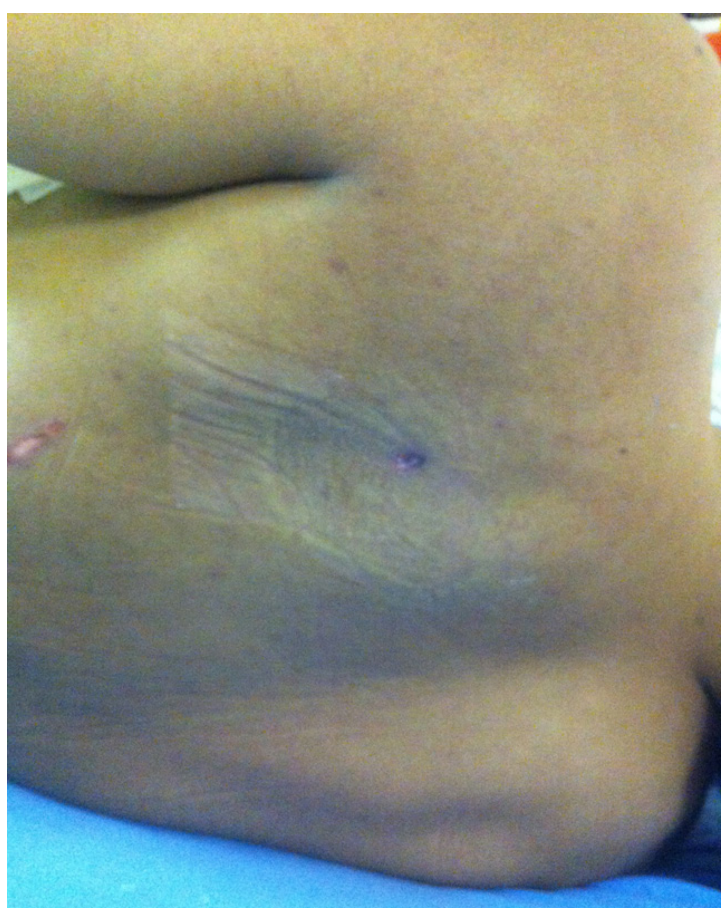

Figure 1. Gunshot entry wound in the posterior left chest. 


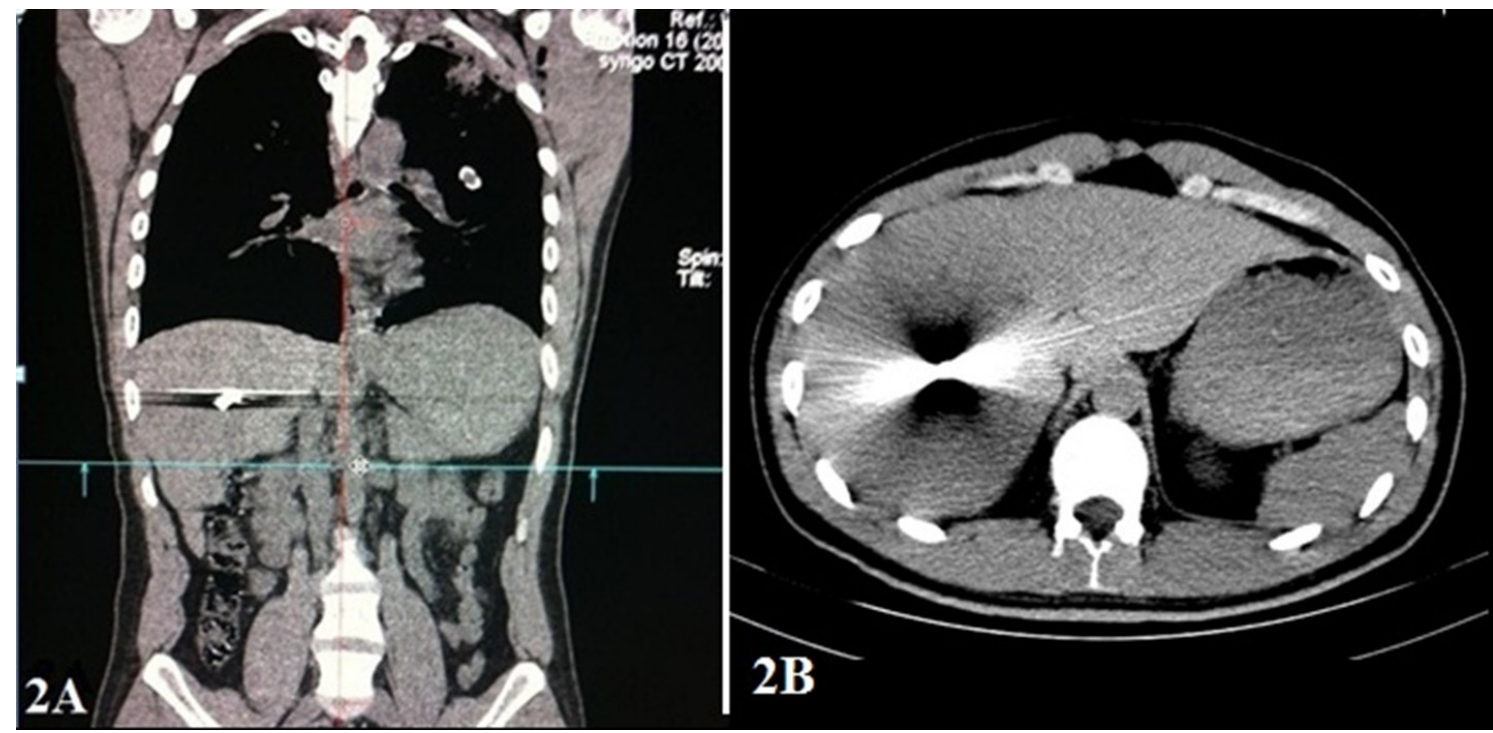

Figure 2. Computed Tomography (non-contrast enhanced) showing evidence of bullet in intra-abdominal (intrahepatic) topography and no sign of trail lesion to parenchymal liver (2A coronal view, 2B axial view).

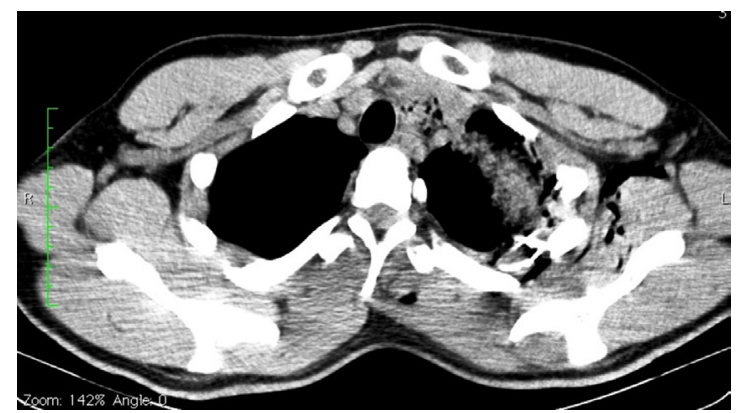

Figure 3. Postoperative contrast-enhanced thoracic Computed Tomography scan showing pulmonary contusion restricted to a trail in the apex of left lung.

Embolization is also more commonly encountered in the arterial system than in the venous system ${ }^{1,8}$. Reports of venous involvement account for just $20-25 \%$ of cases $^{1,9}$. Most venous projectiles embolize from peripheral sites to the heart or vena cava (antegrade migration), but they can also migrate in a retrograde direction ${ }^{2,3,9}$. According to Schroeder et al. ${ }^{1}$, gravity, patient position and negative intra-thoracic pressure likely contribute to retrograde migration down the IVC and into the right common iliac vein. Other factors that have been described as influencing bullet migration include projectile weight, speed, size and shape, muscle movements and breathing, vascular anatomy and flow velocity in the involved vessel ${ }^{2,4}$.

After penetration, intravascular migration usually occurs immediately after projectile entry, including during surgical procedures. However, migration has also been described days, weeks and even 14 years after the initial event ${ }^{2,4,6}$.

In the case presented here, we believe that the bullet was probably inside a branch of the right hepatic vein, since there was no capsular injury to the liver; we also believe that during exploratory laparotomy, when the liver was totally mobilized through its ligaments' section and partially dislocated from the abdominal cavity (lifted upward) in order to search for a possible retro-hepatic phrenic lesion, the projectile migrated back to the IVC, and from there, to the IIV.

Clinically, diagnosis should be suspected in any gunshot wound patient in whom the number of exit wounds is lower than the number of entry wounds, and in whom radiological investigation fails to find a missile in the injured area and/or shows a missile in a remote body area ${ }^{4,6}$.

In this case, although it was not possible to determinate the exact entry site of the bullet into the vessel, the entrance wound and CT scans suggests that bullet entered the left subclavian or left brachiocephalic vein, passed through superior vena cava/right cardiac atrium and descended into the IVC/right hepatic vein and that, after surgical manipulation, it then returned to the IVC and impacted inside the right IIV. The fact that, except for apical contusion trail, there was no pulmonary contusion on $\mathrm{CT}$ is compatible with a high point of entrance into the venous system (left subclavian or left brachiocephalic vein). 

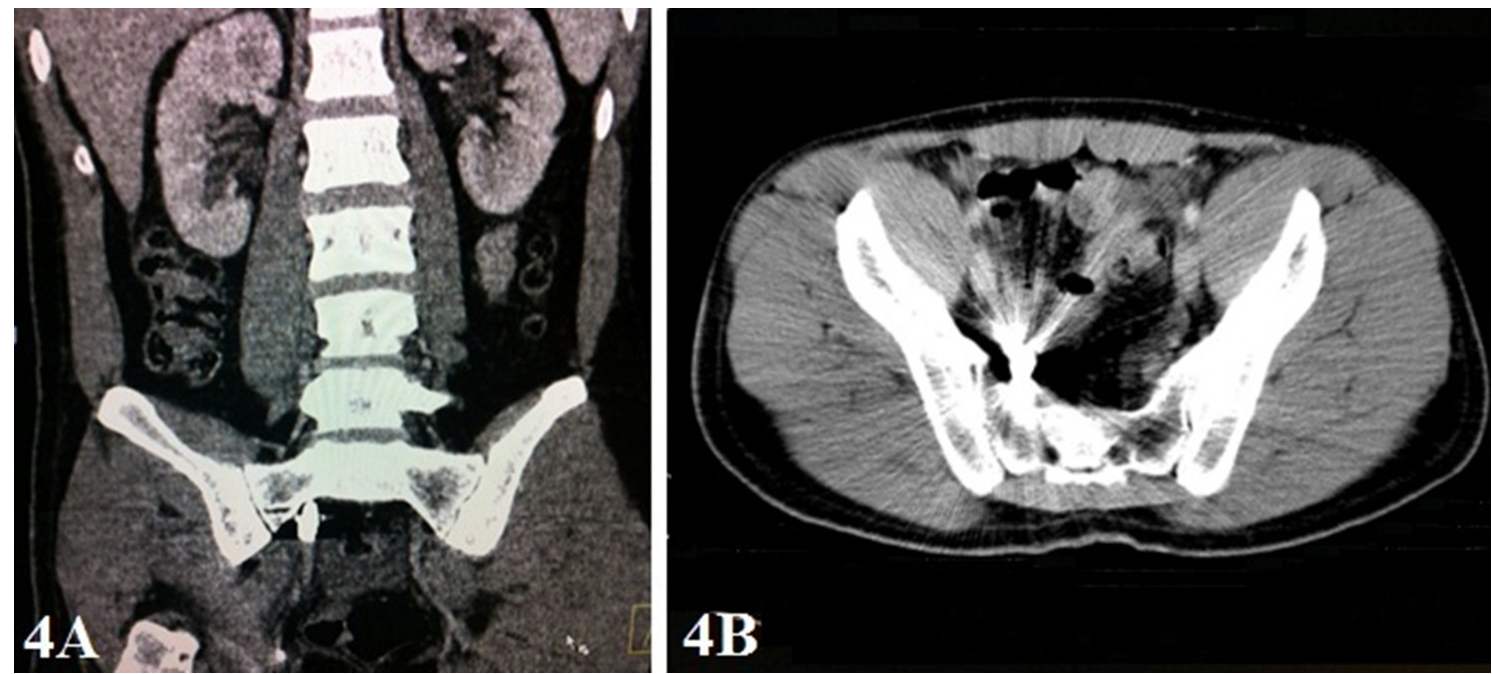

Figure 4. Computed tomography showing the projectile inside the right internal iliac vein after migration (4A coronal view, 4B axial view).

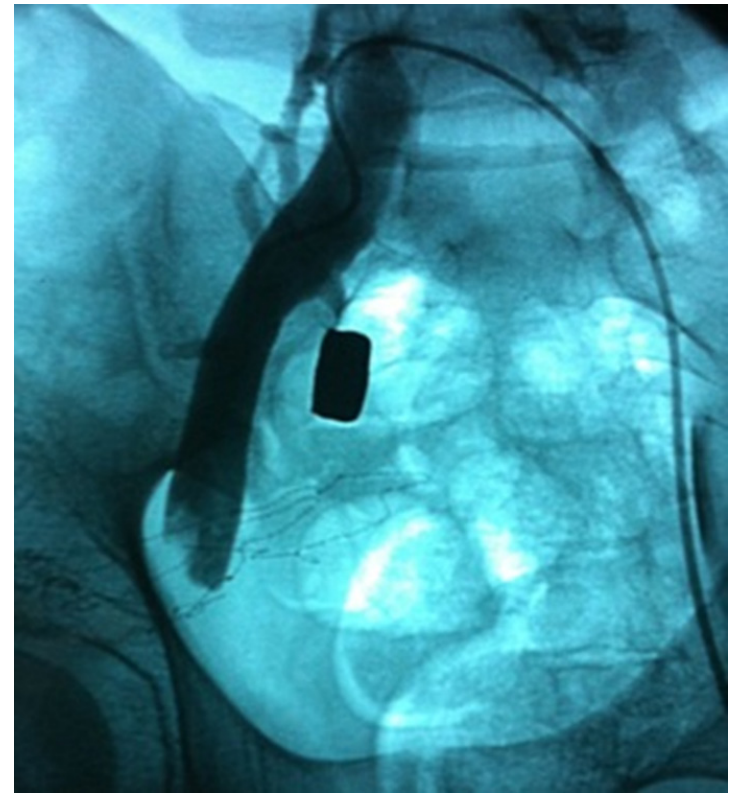

Figure 5. lliocavography demonstrating patent right common and external iliac veins, with preserved lumens and no filling defects; a foreign body (bullet) is impacted in the proximal right internal iliac vein, without opacification of the middle or distal segments.

When an object enters the bloodstream through a cardiac chamber or an injured artery, the patient will probably be hemodynamically unstable and will need an immediate surgical intervention. On the other hand, patients with venous embolism are generally hemodynamically stable (with the exception of those with major venous damage such as vena cava injuries) and the entrance site very often does not need surgical repair because tamponade and hemostasis occur spontaneously. Up to $70 \%$ of these patients may be asymptomatic ${ }^{2,4}$.

When bullet embolization is suspected, management will depend on hemodynamic status, and will usually begin with a CT scan and angiography, the patient's clinical condition permitting. Intravascular ultrasonography can also be considered if an intraluminal location is suspected ${ }^{2,8}$.

In this case, after hemodynamic stabilization, the patient was investigated using X-rays and CT, which showed the bullet in an abdominal topography. Surprisingly, laparotomy showed no abdominal injuries and a sequential CT scan demonstrated a change in bullet topography (from intrahepatic to right IIV), thereby confirming bullet embolism. Venography also helped to confirm the diagnosis. In the present case, as in the literature, imaging methods, such as radiography, CT scan and angiography were therefore critical to confirming diagnosis and to planning treatment ${ }^{4,10}$.

There is little consensus on treatment and indications for removal of bullet emboli ${ }^{1,2,4}$, especially from venous sites. However, most authors recommend conservative treatment in asymptomatic patients and recommend surgical removal of the bullet when there are symptoms or if there is a possibility of complications from leaving it in place. Factors such as the risk of vascular perforation, embolization, ischemia and infection must be weighed against those associated with surgery ${ }^{1}$. Therefore, treatment choice is based on the exact location of the projectile and on the clinical presentation of each patient ${ }^{2,4}$. 
In the case presented here, considering the factors described above and the probable presence of thrombus distal to the bullet's location, since an initial snare retrieval attempt was unsuccessful, it was decided not to remove it due to the potential risk that the procedure could induce thromboembolism (in an asymptomatic patient).

\section{CONCLUSION}

Venous bullet embolism is an extremely rare condition that can potentially be fatal, but which in most cases is asymptomatic. This was a case of a patient with asymptomatic venous bullet embolism in whom diagnostic methods were able to screen and locate the bullet in the right internal iliac vein, allowing safe clinical treatment with a good outcome after failure to retrieve the bullet endovascularly.

\section{REFERENCES}

1. Schroeder ME, Pryor II HI, Chun AK, Rahbar R, Arora S, Vaziri $\mathrm{K}$. Retrograde migration and endovascular retrieval of a venous bullet embolus. J Vasc Surg. 2011;53(4):1113-5. PMid:21215588. http://dx.doi.org/10.1016/j.jvs.2010.11.046

2. Bertoldo U, Enrichens F, Comba A, Ghiselli G, Vaccarisi S, Ferraris M. Retrograde venous bullet embolism: a rare occurrence-case report and literature review. J Trauma. 2004;57:187-92. PMid:15284574. http://dx.doi.org/10.1097/01.TA.0000135490.10227.5C

3. Schurr M, McCord S, Croce M. Paradoxical Bullet Embolism: Case Report and Literature Review. J Trauma. 1996;40(6):1034-6. PMid:8656462. http://dx.doi. org/10.1097/00005373-199606000-00034

4. Machado A, Procópio RJ, Evangelista FB, Kleinsorge GHD, Toledo Afonso C, Navarro TP. Transthoracic retrograde venous bullet embolism: case report and review of the literature. J Vasc Bras. 2008;7:393-6. http://dx.doi.org/10.1590/ S1677-54492008000400017

5. Morais DM Fo, Schimit GTF, Tenório GOS, Sardinha WE, Silvestre JMS, Ramires ED. Peripheral arterial emboli due to bullet projectile: diagnosis confirmed by vascular ultrasound. J Vasc Bras. 2012;11(1):67-72.

6. Adegboyega PA, Nedjema SR, Adekunle A. Arterial bullet embolism resulting in delayed vascular insufficiency: a rationale for mandatory extraction.J Trauma. 1996; 41(3):539-41.PMid:8810979. http://dx.doi.org/10.1097/00005373-199609000-00028

7. Aidinian G, Fox CJ, Rasmussen TE, Gillespie DL.Varied presentations of missile emboli in military combat. J Vasc Surg. 2010;51:214-7. PMid:19703749. http://dx.doi.org/10.1016/j. jvs.2009.06.054

8. Keele KL, Gilbert PM, Aquisto TM, Lichtenberg R, Field TC, Lee BK. Bullet Embolus to the Thoracic Aorta with successful
Endovascular Snare Retrieval. J Vasc Interv Radiol. 2010 Jan;21(1):157-8.

9. Hassan AM, Cooley RS, Papadimos TJ, Fath JJ, Schwann TA, Elsamaloty H. Pulmonary bullet embolism - a safe treatment strategy of a potentially fatal injury: a case report. Patient Saf Surg. 2009;3(1):12-5. PMid:19545380 PMCid:PMC2706800. http:// dx.doi.org/10.1186/1754-9493-3-12

10. Vaquero-Puerta C, Norberto EMS, Merino B, González-Fajardo JA Taylor J. Shotgun wound and pellet embolism to the intracranial carotid artery. J Vasc Surg. 2012;55:535-7. PMid:21963000. http:// dx.doi.org/10.1016/j.jvs.2011.07.091

Correspondence Leonardo Pessoa Cavalcante Hospital Universitário Francisca Mendes - Serviço de Cirurgia Vascular/Endovascular Av. Camapuã, 108 - Cidade Nova ll CEP 69097-720 - Manaus (AM), Brazil E-mail: leonardocavalcante@uol.com.br

Author information LPC is Head, Endovascular Surgery Service in Hospital Universitário Francisca Mendes at Universidade Federal do Amazonas (UFAM), Manaus (AM), Brazil.

MVB is Head, Vascular Surgery Service in Hospital Universitário Francisca Mendes at Universidade Federal do Amazonas (UFAM) Manaus (AM), Brazil.

RDR and MHP are Vascular surgeons, Vascular Surgery Service in Hospital Universitário Francisca Mendes at Universidade Federal do Amazonas (UFAM), Manaus (AM), Brazil.

JESS and AOA are Resident physicians in Vascular Surgery, Vascular Surgery Service in Hospital Universitário Francisca Mendes/Hospital Universitário Getúlio Vargas at Universidade Federal do Amazonas (UFAM), Manaus (AM), Brazil.

PSL is Vascular surgeon, Medical Residency Program in Hospital Universitário Francisca Mendes/Hospital Universitário Getúlio Vargas at Universidade Federal do Amazonas (UFAM), Manaus (AM), Brazil.

RMP is Medical student at Universidade Federal do Amazonas, Manaus (AM), Brazil.

Author contributions Conception and design: JESS, LPC, RMP Analysis and interpretation: MVB, MHP, RDR

Data collection: JESS, PSL, AOA

Writing the article: JESS, RMP, LPC Critical revision of the article: $L P C, M V B, M H P, R D R$ Final approval of the article*: JESS, RMP, LPC, MVB, MHP, RDR, PSL,

AOA Statistical analysis: N/A Overall responsibility: JESS Obtained funding: None

*All authors should have read and approved of the final version of the article submitted to J Vasc Bras. 